\title{
The developmental origins of adult disease
}

\author{
Lisa A. Joss-Moore and Robert H. Lane \\ Division of Neonatology, Department of Pediatrics, University of Utah, Salt Lake, Utah, USA
}

\begin{abstract}
Purpose of review-Intrauterine growth restriction (IUGR) is associated with an increased propensity to develop adult onset disease and is described by the developmental origins of adult disease hypothesis. Sequelae of fetal growth restriction include metabolic disease as well as nonmetabolic disorders. Although it has become clear that the morbidities associated with IUGR are complex and result from disruptions to multiple pathways and multiple organs, the mechanisms driving the long-term effects are only just beginning to be understood.
\end{abstract}

\begin{abstract}
Recent findings-IUGR affects most organ systems by either interrupting developmental processes such as apoptosis or producing lasting changes to levels of key regulatory factors. Both of these are associated with an often persistent change in gene expression. Epigenetic modulation of transcription is a mechanism that is at least partially responsible for this. IUGR is accompanied by changes in the quantity and activity of enzymes responsible for making modifications to chromatin as well as global and gene-specific modifications of chromatin.
\end{abstract}

Summary-The subtle adjustments needed to ensure developmental plasticity in IUGR are provided by epigenetic modulation of critical genes. Translating the messages of the epigenetic profile and identifying the players that mediate the effects remains one of the major challenges in the field. An understanding of the mechanisms driving the epigenetic changes will facilitate identification of dietary and pharmaceutical approaches that can be applied in the postnatal period.

\section{Keywords}

epigenetics; intrauterine growth restriction; programming

\section{Introduction}

The Developmental Origins of Adult Disease Hypothesis describes the origin of adult disease in terms of fetal developmental 'plasticity' or the ability of the fetus to respond to poor in-utero conditions [1]. A wealth of epidemiological evidence has provided a convincing link between a sub-optimal gestational environment and an increased propensity to develop adult onset metabolic disease [2,3]. Intrauterine growth restriction (IUGR) provides a useful model for examination of the developmental origins hypothesis and may result from perturbations in placental blood flow, poor maternal nutrition or maternal exposure to toxins [4-6].

To effectively manage IUGR infants postnatally and to minimize the adult consequences of poor prenatal growth, it is essential to understand the mechanisms by which a prenatal insult results in adult disease. This will facilitate interventions to identify a postnatal 'window' in which positive changes can be made and allow development of evidence-based assessments of the effects of specific macronutrients and micronutrients. This review will focus on recent 
advances in understanding of the mechanisms by which the perinatal environment can have a lasting impact on adult phenotype.

\section{Outcomes of intrauterine growth restriction}

The development of adult morbidities as a result of IUGR is complex and involves multiple pathways and multiple organs. Generally speaking, the majority of morbidities associated with IUGR can be split into metabolic and nonmetabolic effects (Table 1 Table 1). The search for one specific organ or pathway that is disrupted by IUGR has been futile. Given the metabolic nature of the primary morbidities associated with IUGR, this is not surprising. Mammalian metabolism is a highly complex, finely choreographed interaction between many interconnected pathways and intermediates. IUGR affects many of these pathways and intermediates, and these effects are dependent on sex, the specific nature of the insult, the gestational timing of the insult and the rate of postnatal growth.

\section{Metabolic effects of intrauterine growth restriction}

Adult onset metabolic disturbances in IUGR individuals involve the adipose tissue, liver, $\beta$ cells kidney and vascular system. Disruption of lipid metabolism in the adipose tissue and liver contribute to dyslipidemia, fatty liver and obesity. Increased hepatic glucose production, $\beta$-cell dysfunction and impaired peripheral glucose uptake contribute to impaired glucose homeostasis in IUGR. Changes in structure and function of the kidney and vasculature contribute to hypertension and other cardiovascular morbidities. An important and interesting consideration is the impact of sex on the development of metabolic disease in IUGR, with men appearing to be more severely effected [7-10].

The prevalence of obesity, particularly visceral obesity, as an outcome of poor fetal growth is well documented [11-13] and can arise as a result of altered adipogenesis or increased energy intake or both. Increased visceral adiposity and increased visceral levels of pro-adipogenic transcription factors such as peroxisome proliferator activated receptor $\gamma(\operatorname{PPAR} \gamma)$ are seen as a result of lower birth weight in sheep regardless of whether the low birth weight is the result of IUGR [14 ${ }^{\circ}$ ] or simply the result of natural population variation [15]. Increased visceral adiposity is also associated with the rate of postnatal growth in offspring that were previously growth restricted $\left[16^{*}, 17\right]$. Interestingly, minimizing postnatal growth in IUGR rat pups alleviates the obesity and metabolic consequences of IUGR $\left[16^{\circ}\right]$.

Impaired hepatic lipid regulation and the development of fatty liver are associated with the metabolic syndrome and altered plasma lipids. Maternal food restriction in rats produces IUGR offspring with smaller hepatic lobules and sex-specific alterations in hepatic lipid regulation. In male rats, IUGR increases hepatic triglyceride and cholesterol content, whereas in female rats, IUGR decreases hepatic cholesterol. In addition, male rats have increased hepatic expression of genes involved in lipogenesis as well as increased markers of inflammation $[18,19]$.

The liver is also an important site for glucose homeostasis. Hepatic glucose production, along with $\beta$-cell function and insulin sensitivity are affected by IUGR and result in the insulin resistance and type 2 diabetes observed in IUGR adults [11,20-22]. Late gestational fetal hypoglycemia in sheep increases gluconeogenic enzymes and gluconeogenis without a concomitant change in liver glycogen [23*0. Pancreatic $\beta$-cells are also structurally and functionally affected by IUGR, again with a sex-specific difference and men being more severely affected [24].

A propensity toward renal insufficiency and adult onset hypertension is also associated with IUGR and accompanied by altered renal development and reduced nephron number in IUGR 
offspring $[25,26]$. These changes are associated with altered expression of renal transcription factors driving development [27], altered glucocorticoid signaling molecules [28] and increased apoptotic processes [29]. In an attempt to elucidate the cause of sex effects in IUGR, recent studies have examined the effect of estrogen and testosterone on hypertension and vascular dysfunction and shown that estrogen can be associated with a protective effect [30] and testosterone with a deleterious effect [31].

\section{Nonmetabolic effects of intrauterine growth restriction}

Structural changes in organs not directly associated with the metabolic syndrome are also induced by IUGR. Although not as well documented as the metabolic effects, IUGR also predisposes human infants to an increased risk of chronic lung disease (CLD) at birth [3234]. Animal models of IUGR have shown that impaired lung development during late gestational fetal growth results in altered lung morphology at birth, consistent with that seen in CLD $[35,36]$. These changes are accompanied by decreased active p53, as well as decreased mRNA of other pro-apoptotic targets downstream of p53, and increased mRNA levels of Bcl-2, an antiapoptotic gene downregulated by p53 [36].

Finally, although the asymmetric nature of IUGR induced by late gestational insults was once considered to have a 'brain-sparing' effect, the brain is also affected both structurally and functionally by IUGR. In humans, MRI analysis of adolescents who were born preterm shows altered brain structure, with decreased caudate volume and a corresponding decrease in IQ scores [37]. Interestingly, this cohort can be separated into groups that received either a standard or high nutrient postnatal diet, with the infants receiving high-nutrient diet displaying improved cognitive performance at 18 months and at 7-8 years compared with those who received the standard-nutrient diet. The effect was particularly pronounced in male infants [38]. Although these studies address the nutrient content of the postnatal diet, others have examined the association of cognitive function and BMI with postnatal rate of growth in term IUGR infants. Rapid weight gain over the first 4 months postnatally after IUGR predicts both increased BMI and decreased cognitive scores at 7 years of age [39 ${ }^{\circ}$. It is important to note, however, that poor postnatal growth was also associated with decreased cognitive scores [39॰ $]$.

These studies show that, on a molecular level, IUGR can affect tissue in two ways. First, IUGR can produce structural changes in tissue. This reflects early interruptions in developmental processes, particularly those involving apoptosis. Second, IUGR results in altered levels of homeostatic regulating factors and subsequent changes to intercellular and intracellular signaling. Both these phenomena result from alterations in gene expression that occur in response to IUGR. A key mechanistic concept arises from the observation that many of the changes in gene expression that are observed in the neonatal period persist into adulthood. These persistent changes in gene expression have lead investigators to deduce that epigenetics is an underlying mechanism in the developmental origins of disease.

\section{Epigenetics}

The information stored in the genetic material predicts the potential phenotype of an organism; it is, however, the transcription of that information that produces the phenotype. Transcriptional regulation can be provided in the short term by signal transduction and transcription factor activation or over the long term by epigenetics. The persistent nature of altered mRNA levels of key genes in IUGR suggests epigenetic regulation of gene transcription.

Epigenetics refers to heritable changes in gene transcription caused by mechanisms other than changes in the underlying DNA sequence. One of these mechanisms involves modifications to chromatin; the DNA and protein complex that forms the fundamental structure of chromosomes. The reversible epigenetic modifications include direct methylation of DNA as 
well as a vast array of histone modifications that include acetylation and methylation [40]. In the context of chromatin, these modifications can be read collectively as an epigenetic 'profile' or 'code'. The epigenetic profile of chromatin regulates the transcription of genes by affecting DNA interactions with the transcription machinery and other regulatory moieties. In addition to the already well explored functions of epigenetics in imprinting and gene silencing, epigenetics provides a means of modulating gene transcription; that is, adjusting the level of expression of genes already being transcribed. This will elicit subtle modifications in the phenotype and provide the 'plasticity' necessary for the fetal genotype to respond in the face of IUGR.

IUGR is accompanied by changes in the quantity and activity of enzymes responsible for making modifications to chromatin. In the IUGR rat brain at birth, global decreases in DNA methylation and increases in histone 3 (H3) acetylation on lysine 9 (K9) and K14 are observed [41]. These changes are accompanied by a concomitant decrease in the DNA methyltransferase Dnmt1, the methyl-CpG binding protein MeCP2, and the histone deacetylase HDAC1 [41]. Interestingly, the modifications to chromatin in IUGR rat brains are sex dependent, with a divergence in global acetylation occurring at $\mathrm{d} 21$ when female brains continue to be characterized by increased site-specific acetylation, whereas male brains become characterized by decreased acetylation at $\mathrm{K} 9$ and $\mathrm{K} 14$ of $\mathrm{H} 3$ [41]. Liver chromatin modifications are also affected by IUGR with persistent increases in acetylation of H3K9 and K14 [42], as well as reduced hepatic expression of Dnmt1 [43]. IUGR is also associated with specific changes in the IUGR promoter histones of skeletal muscle GLUT4 and $\beta$-cell Pdx 1 [44,45 ${ }^{\circ}$. Interestingly, modified histones are not only associated with limited fetal nutrition, a non-human primate model of maternal obesity also results in hyperacetylation of specific lysines of histone 3 and reduced mRNA, protein levels and activity of HDAC1 [46** $]$.

The search for altered epigenetic phenomena in IUGR has shown that the modulation of transcription required for subtle adjustments may utilize the epigenetic profile in a slightly different manner than that used to produce absolute gene silencing or activation. In other words, once a gene is being expressed, IUGR appears to alter the epigenetic profile in a unique manner that results in a subtle adjustment to the level of transcription. This information is supported by studies that look at regions of the gene traditionally considered important for transcriptional regulation and studies that have examined the entire gene.

In studies examining the proximal promoter region of the homeobox 1 transcription factor, $\mathrm{Pdx} 1$, IUGR results in increasing methylation of $\mathrm{CpG}$ dinucleotides as the offspring age and this is accompanied by a decrease in the expression of Pdx 1 mRNA. What is interesting in this study is that even though IUGR offspring have reduced Pdx 1 transcription at birth and 2 weeks of age, the appearance of methylation in the promoter is not detectable until 6 months of age $\left[45^{\circ}, 47\right]$. Histone modifications in the region of the promoter are, however, present at birth and presumably precipitate the presence of promoter methylation in later life. The hepatic dual specificity phosphatase, DUSP5, gene is also affected by IUGR in an interesting manner. IUGR decreases mRNA levels of hepatic DUSP5 in conjunction with decreased methylation of five CpGs contained within exon 2 of DUSP5; this apparent paradox of decreased transcription being associated with decreased methylation is supported by evidence that downstream methylation may be involved in promoting transcription [48].

The subtle adjustments needed to ensure developmental plasticity in the context of a fixed genotype are provided by epigenetics. The progression of understanding of the role of epigenetics in the developmental origins hypothesis began with the observation that IUGR induced lasting changes in gene expression and that this was accompanied by changes in levels and activities of chromatin-modifying enzymes. This was followed by characterizations of changes in global DNA methylation and histone modifications. The examination of chromatin 
associated with specific key genes is now yielding a wealth of information about IUGR-induced modifications to chromatin. The next step is to understand how IUGR results in these changes and to interpret the language of the chromatin modifications. This will require detailed analysis of entire genes in the context of multiple models of IUGR and in multiple tissues.

\section{Conclusion}

The consequences of poor in-utero growth are relatively constant. Although the details may vary, depending on the timing and severity of insult, the overall mechanism appears to involve epigenetic modifications to chromatin associated with critical genes. The developmental origins field is in an exciting time with studies now beginning to characterize changes to the epigenetic profile of chromatin in response to IUGR. This should be followed by identification of the environmental and nutritional signals that result in these changes. Translating the messages of the epigenetic profile and identifying the players that mediate effects remains one of the major challenges in understanding the manner in which epigenetics link a perinatal insult to an adult phenotype. Such an understanding will facilitate identification of dietary and pharmaceutical approaches that can be applied in the postnatal period.

\section{Acknowledgement}

The study was supported by NIH.

\section{References}

References and recommended reading

Papers of particular interest, published within the annual period of review, have been highlighted as:

- of special interest

$\bullet$ of outstanding interest

Additional references related to this topic can also be found in the Current World Literature section in this issue (pp. 000-000).

1. Barker DJ. The developmental origins of chronic adult disease. Acta Paediatr Suppl 2004;93:26-33. [PubMed: 15702667]

2. Painter RC, Roseboom TJ, Bleker OP. Prenatal exposure to the Dutch famine and disease in later life: an overview. Reprod Toxicol 2005;20:345-352. [PubMed: 15893910]

3. Syddall HE, Sayer AA, Simmonds SJ, et al. Birth weight, infant weight gain, and cause-specific mortality: the Hertfordshire Cohort Study. Am J Epidemiol 2005;161:1074-1080. [PubMed: 15901628]

4. Neerhof MG, Thaete LG. The fetal response to chronic placental insufficiency. Semin Perinatol 2008;32:201-205. [PubMed: 18482622]

5. Hendrix N, Berghella V. Nonplacental causes of intrauterine growth restriction. Semin Perinatol 2008;32:161-165. [PubMed: 18482615]

6. Kinzler WL, Vintzileos AM. Fetal growth restriction: a modern approach. Curr Opin Obstet Gynecol 2008;20:125-131. [PubMed: 18388811]

7. Parker L, Lamont DW, Unwin N, et al. A lifecourse study of risk for hyperinsulinaemia, dyslipidaemia and obesity (the central metabolic syndrome) age 49-51 years. Diabet Med 2003;20:406-415. [PubMed: 12752491]

8. Flanagan DE, Moore VM, Godsland IF, et al. Fetal growth and the physiological control of glucose tolerance in adults: a minimal model analysis. Am J Physiol Endocrinol Metab 2000;278:E700-E706. [PubMed: 10751205] 
9. Chen SJ, Vohr BR, Oh W. Effects of birth order, gender, and intrauterine growth retardation on the outcome of very low birth weight in twins. J Pediatr 1993;123:132-136. [PubMed: 8320607]

10. Sugden MC, Holness MJ. Gender-specific programming of insulin secretion and action. J Endocrinol 2002;175:757-767. [PubMed: 12475386]

11. Ross MG, Beall MH. Adult sequelae of intrauterine growth restriction. Semin Perinatol 2008;32:213218. [PubMed: 18482624]

12. Cottrell EC, Ozanne SE. Early life programming of obesity and metabolic disease. Physiol Behav 2008;94:17-28. [PubMed: 18155097]

13. Wells JC, Chomtho S, Fewtrell MS. Programming of body composition by early growth and nutrition. Proc Nutr Soc 2007;66:423-434. [PubMed: 17637095]

14-. Duffield JA, Vuocolo T, Tellam R, et al. Placental restriction of fetal growth decreases IGF1 and leptin mRNA expression in the perirenal adipose tissue of late gestation fetal sheep. Am J Physiol Regul Integr Comp Physiol 2008;294:R1413-R1419. [PubMed: 18272661]• of special interestThis study addresses an important issue in IUGR, that is the contribution of adipokine gene expression in visceral adipose tissue

15. Muhlhausler BS, Ritorto V, Schultz C, et al. Birth weight and gender determine expression of adipogenic, lipogenic and adipokine genes in perirenal adipose tissue in the young adult sheep. Domest Anim Endocrinol 2008;35:46-57. [PubMed: 18308504]

16••. Desai M, Gayle D, Babu J, Ross MG. The timing of nutrient restriction during rat pregnancy/ lactation alters metabolic syndrome phenotype. Am J Obstet Gynecol 2007;196:555 e1-555 e7. [PubMed: 17547893] • of outstanding interestIn this study, the authors go beyond fetal growth restriction and address the effects of postnatal nutrient availability on the development of metabolic syndrome in IUGR

17. De Blasio MJ, Gatford KL, Robinson JS, Owens JA. Placental restriction of fetal growth reduces size birth and alters postnatal growth, feeding activity, and adiposity in the young lamb. Am J Physiol Regul Integr Comp Physiol 2007;292:R875-R886. [PubMed: 17023666]

18. Choi GY, Tosh DN, Garg A, et al. Gender-specific programmed hepatic lipid dysregulation in intrauterine growth-restricted offspring. Am J Obstet Gynecol 2007;196:477 e1-477 e7. [PubMed: 17466711]

19. Magee TR, Han G, Cherian B, et al. Down-regulation of transcription factor peroxisome proliferatoractivated receptor in programmed hepatic lipid dysregulation and inflammation in intrauterine growth-restricted offspring. Am J Obstet Gynecol 2008;199:271 e1-271 e5. [PubMed: 18667178]

20. Reusens B, Ozanne SE, Remacle C. Fetal determinants of type 2 diabetes. Curr Drug Targets 2007;8:935-941. [PubMed: 17691930]

21. Simmons RA. Role of metabolic programming in the pathogenesis of beta-cell failure in postnatal life. Rev Endocr Metab Disord 2007;8:95-104. [PubMed: 17680370]

22. Devaskar SU, Thamotharan M. Metabolic programming in the pathogenesis of insulin resistance. Rev Endocr Metab Disord 2007;8:105-113. [PubMed: 17657604]

23••. Rozance PJ, Limesand SW, Barry JS, et al. Chronic late-gestation hypoglycemia upregulates hepatic PEPCK associated with increased PGC1alpha mRNA and phosphorylated CREB in fetal sheep. Am J Physiol Endocrinol Metab 2008;294:E365-E370. [PubMed: 18056789]•• of outstanding interestIn this study, the authors have examined the role of fetal hypoglycemia on hepatic glucose production in a thorough examination of the molecular components of gluconeogenesis

24. Gatford KL, Mohammad SN, Harland ML, et al. Impaired beta-cell function and inadequate compensatory increases in beta-cell mass after intrauterine growth restriction in sheep. Endocrinology 2008;149:5118-5127. [PubMed: 18535100]

25. Ojeda NB, Grigore D, Alexander BT. Intrauterine growth restriction: fetal programming of hypertension and kidney disease. Adv Chronic Kidney Dis 2008;15:101-106. [PubMed: 18334233]

26. Hershkovitz D, Burbea Z, Skorecki K, Brenner BM. Fetal programming of adult kidney disease: cellular and molecular mechanisms. Clin J Am Soc Nephrol 2007;2:334-342. [PubMed: 17699433]

27. Abdel-Hakeem AK, Henry TQ, Magee TR, et al. Mechanisms of impaired nephrogenesis with fetal growth restriction: altered renal transcription and growth factor expression. Am J Obstet Gynecol 2008;199:252 e1-252 e7. [PubMed: 18639218] 
28. Baserga M, Hale MA, Wang ZM, et al. Uteroplacental insufficiency alters nephrogenesis and downregulates cyclooxygenase-2 expression in a model of IUGR with adult-onset hypertension. Am J Physiol Regul Integr Comp Physiol 2007;292:R1943-R1955. [PubMed: 17272666]

29. Baserga M, Hale MA, Ke X, et al. Uteroplacental insufficiency increases p53 phosphorylation without triggering the p53-MDM2 functional circuit response in the IUGR rat kidney. Am J Physiol Regul Integr Comp Physiol 2006;291:R412-R418. [PubMed: 16914427]

30. Musha Y, Itoh S, Hanson MA, Kinoshita K. Does estrogen affect the development of abnormal vascular function in offspring of rats fed a low-protein diet in pregnancy? Pediatr Res 2006;59:784789. [PubMed: 16641213]

31. Ojeda NB, Grigore D, Yanes LL, et al. Testosterone contributes to marked elevations in mean arterial pressure in adult male intrauterine growth restricted offspring. Am J Physiol Regul Integr Comp Physiol 2007;292:R758-R763. [PubMed: 16917022]

32. Aucott SW, Donohue PK, Northington FJ. Increased morbidity in severe early intrauterine growth restriction. J Perinatol 2004;24:435-440. [PubMed: 15116139]

33. Bardin C, Zelkowitz P, Papageorgiou A. Outcome of small-for-gestational age and appropriate-forgestational age infants born before 27 weeks of gestation. Pediatrics 1997;100:E4. [PubMed: 9233975]

34. Stein CE, Kumaran K, Fall CH, et al. Relation of fetal growth to adult lung function in south India. Thorax 1997;52:895-899. [PubMed: 9404378]

35. Lipsett J, Tamblyn M, Madigan K, et al. Restricted fetal growth and lung development: a morphometric analysis of pulmonary structure. Pediatr Pulmonol 2006;41:1138-1145. [PubMed: 17063475]

36. O'Brien EA, Barnes V, Zhao L, et al. Uteroplacental insufficiency decreases p53 serine-15 phosphorylation in term IUGR rat lungs. Am J Physiol Regul Integr Comp Physiol 2007;293:R314R322. [PubMed: 17428897]

37. Isaacs EB, Gadian DG, Sabatini S, et al. The effect of early human diet on caudate volumes and IQ. Pediatr Res 2008;63:308-314. [PubMed: 18287970]

38. Lucas A, Morley R, Cole TJ. Randomised trial of early diet in preterm babies and later intelligence quotient. BMJ 1998;317:1481-1487. [PubMed: 9831573]

39•. Pylipow M, Spector LG, Puumala SE, et al. Early postnatal weight gain, intellectual performance, and body mass index 7 years of age in term infants with intrauterine growth restriction. J Pediatr. in press• of special interestThis article addresses the connection between the rate of postnatal growth in humans and neurocognitive deficit

40. Kouzarides T. Chromatin modifications and their function. Cell 2007;128:693-705. [PubMed: 17320507]

41. Ke X, Lei Q, James SJ, et al. Uteroplacental insufficiency affects epigenetic determinants of chromatin structure in brains of neonatal and juvenile IUGR rats. Physiol Genomics 2006;25:16-28. [PubMed: 16380407]

42. Fu Q, McKnight RA, Yu X, et al. Growth retardation alters the epigenetic characteristics of hepatic dual specificity phosphatase 5. FASEB J 2006;20:2127-2129. [PubMed: 16940436]

43. Lillycrop KA, Slater-Jefferies JL, Hanson MA, et al. Induction of altered epigenetic regulation of the hepatic glucocorticoid receptor in the offspring of rats fed a protein-restricted diet during pregnancy suggests that reduced DNA methyltransferase- 1 expression is involved in impaired DNA methylation and changes in histone modifications. Br J Nutr 2007;97:1064-1073. [PubMed: 17433129]

44. Raychaudhuri N, Raychaudhuri S, Thamotharan M, Devaskar SU. Histone code modifications repress glucose transporter 4 expression in the intrauterine growth-restricted offspring. J Biol Chem 2008;283:13611-13626. [PubMed: 18326493]

45•. Park JH, Stoffers DA, Nicholls RD, Simmons RA. Development of type 2 diabetes following intrauterine growth retardation in rats is associated with progressive epigenetic silencing of Pdx 1. J Clin Invest 2008;118:2316-2324. [PubMed: 18464933]• of special interestThis study offers a comprehensive examination of the IUGR-induced modifications to chromatin and chromatinassociated factors within the promoter region of $\mathrm{Pdx} 1$

46••. Aagaard-Tillery KM, Grove K, Bishop J, et al. Developmental origins of disease and determinants of chromatin structure: maternal diet modifies the primate fetal epigenome. J Mol Endocrinol 
2008;41:91-102. [PubMed: 18515302] •• of outstanding interestThis article is one of the first accounts of maternal dietary influence on the epigenome of the offspring in a nonhuman primate

47. Stoffers DA, Desai BM, DeLeon DD, Simmons RA. Neonatal exendin-4 prevents the development of diabetes in the intrauterine growth retarded rat. Diabetes 2003;52:734-740. [PubMed: 12606515]

48. Murrell A, Heeson S, Bowden L, et al. An intragenic methylated region in the imprinted Igf2 gene augments transcription. EMBO Rep 2001;2:1101-1106. [PubMed: 11743023] 
Table 1

Adult phenotypes of intrauterine growth restriction

$\begin{array}{ll}\text { Metabolic Nonmetabolic } & \text { Nonm }\end{array}$

Metabolic

Dyslipidemia

Hypertension

Insulin resistance

Poor postnatal growth

Renal insufficiency
Attention deficit disorder

Chronic lung disease

Immunodeficiency

Neurodevelopmental delay

Schizophrenia 